\title{
Gammaherpesvirus infections in equids: a review
}

This article was published in the following Dove Press journal:

Veterinary Medicine: Research and Reports

I April 2015

Number of times this article has been viewed

\section{Maria Luisa Marenzoni' \\ Valentina Stefanetti ${ }^{1}$ \\ Maria Luisa Danzetta' \\ Peter Joseph Timoney ${ }^{2}$ \\ 'Department of Veterinary Medicine, University of Perugia, Perugia, Italy; ${ }^{2}$ Department of Veterinary Science, Maxwell H Gluck Equine Research Center, Lexington, KY, USA}

Correspondence: Maria Luisa Marenzoni Department of Veterinary Medicine, University of Perugia, via S Costanzo 4, 06126 Perugia, Italy

Tel +390755857720

Fax +39075585 7765

Email marialuisa.marenzoni@unipg.it
Abstract: Although the first equine gammaherpesvirus was identified over 50 years ago, the isolation and characterization of other members of this virus group has been relatively recent. Even so, numerous clinical syndromes have been identified in equid species in association with these viruses. Equid gammaherpesviruses are a genetically heterogeneous viral subfamily, the function of which in host immune modulation and disease pathogenesis has not yet been elucidated. While they share similarities with gammaherpesviruses in humans, the role they play in their relationship with the host is the subject of continued interest and research. Their widespread presence in horses and other equid species provides a considerable challenge in linking them with particular clinical and pathological conditions and in defining their significance from a diagnostic and therapeutic viewpoint. The present review provides an update on the taxonomy, epidemiology, and clinical syndromes, especially respiratory, reported in association with gammaherpesvirus infection in horses, donkeys, and other equid species.

Keywords: equid gammaherpesviruses, horses, donkeys, other equid species, equine multinodular pulmonary fibrosis

\section{Introduction}

The first gammaherpesvirus $(\gamma-\mathrm{HV})$ in equids $(\gamma$-EHV) was isolated from a horse with upper respiratory tract disease in 1962. It was referred to as an equine cytomegalovirus. ${ }^{1,2}$ In 1987 , other $\gamma$-EHVs were described. ${ }^{3-5}$ Although initially considered betaherpesviruses, they were subsequently reclassified as $\gamma$-EHVs and designated equid herpesvirus 2 (EHV-2) and equid herpesvirus 5 (EHV-5). ${ }^{5}$ The first asinine $\gamma$-HV was isolated from an asymptomatic donkey in $1988 .^{6}$

Since then, $\gamma$-EHV infections have been detected worldwide in a range of equid species. It has been postulated that these viruses are the result of a coevolution process with their hosts lasting for millions of years. ${ }^{7,8}$ Infections have been reported in horses both in the absence of clinical signs and in association with a wide range of clinical settings. This makes it difficult to unequivocally define what role, if any, is played by these viruses in disease causation. ${ }^{7}$ Gammaherpesviruses are generally characterized by a narrow host range and slow replication cycles. They cause acute infections in permissive cells such as epithelial cells, whereas they establish lifelong latency upon infection of nonproductive cells, like B lymphocytes and/or T lymphocytes. ${ }^{9}$ Unlike alphaherpesviruses and betaherpesviruses, $\gamma$-HV usually avoid giving rise to lytic infection upon cell entry and establish latency within the host cell nucleus as circular episomal DNA. For this reason, they generally do not result in significant clinical signs 
upon primary infection of their natural host species, whereas they can cause severe disease in related nonhost species..$^{10,11}$

Another possibility is that $\gamma$-HV may establish a symbiotic relationship with the host, even protecting it from subsequent infection by means of heightened innate immune activation that is maintained by latent viral infection. ${ }^{12}$

A characteristic of $\gamma$-HV is lymphotropism, sometimes associated with aberrations of these cells both in vitro (with the immortalization of B lymphocytes) and in vivo (with the development of transient and chronic lymphoproliferative disorders). ${ }^{9}$ Recent reports have also described these events in infected equids. ${ }^{13-17}$

Moreover, these viruses are characterized by a wide genomic heterogeneity. ${ }^{18-23}$ This property is believed to influence the dynamics of the infection, resulting in repeated infections and viral recombination during the life of the horse. ${ }^{24-26}$ Genomic heterogeneity is also relevant from the viewpoint of diagnostic testing in that it emphasizes the importance of using conserved regions of the viral genome when attempting their detection. ${ }^{27,28}$

Gammaherpesvirus infections directly involve the immune response which it would appear they are able to modulate. Examination of the EHV-2 genome has shown that it encodes a number of genes potentially involved in downregulation of the host immune response, including an interleukin-10 homolog g6,29,30 $^{2}$ and proteins similar to chemokine receptors..$^{25,26,31-33}$ The immunomodulatory potential of these proteins may be exploited by herpesviruses that encode viral chemokine receptor "mimics", by subversion of host immunity in the vicinity of infected cells or otherwise enhancing virus replication and/or dissemination. ${ }^{34,35}$

The host immunity modulation property of $\gamma$-HV could have a role to play in secondary infections. Bacterial infections associated with $\gamma$-HV infection have been described. ${ }^{36-43}$ Recently, studies of $\gamma$-HV infection by murine herpesvirus 68 , which can cause persistent infection in mice, found that this virus was able to render the uterine cervix susceptible to systemic viral infection during pregnancy and promote the passage of bacteria through the cervical canal to the uterus from the distal female reproductive tract; noninfected pregnant mice were normally able to prevent this taking place. ${ }^{39}$

$\gamma$-EHV infections, especially those associated with pulmonary fibrosis, have been proposed as a model to study similar pathologies in humans. ${ }^{44-46}$ Conversely, knowledge gained from other $\gamma$-HV infections, especially murine and human, could be used in helping understand particular equid infections.
The genetic heterogeneity of this subfamily, their function in host modulation related to host gene homologs, similarity to other human $\gamma$-HVs, and recent discoveries about their association with the pathogenesis of certain clinical syndromes, emphasize the significance of $\gamma$-EHVs as a subject for further study.

\section{Taxonomy}

According to the latest taxonomic classification, the order Herpesvirales comprises three families, ie, Herpesviridae, Alloherpesviridae, and Malacoherpesviridae. ${ }^{47}$ The Herpesviridae family includes mammalian, avian, and reptilian viruses. It is further divided into three subfamilies, namely the Alphaherpesvirinae, Betaherpesvirinae, and Gammaherpesvirinae. The Alphaherpesvirinae subfamily includes equid herpesvirus type 1 (EHV-1, equine abortion virus), EHV-3 (equine coital exanthema virus), EHV-4 (equine rhinopneumonitis virus), EHV-6 (asinine herpesvirus 1, ASH-1), EHV-8 (asinine herpesvirus 3, ASH-3), and EHV-9 (gazelle herpesvirus 1), all belonging to the genus Varicellovirus. Unlike other equid herpesviruses, EHV-9 was originally isolated from a gazelle and designated as gazelle herpesvirus type 1 ; however, its serological crossreactivity and genetic similarity with equid herpesviruses indicated that it is an equine herpesvirus, showing a wide host range and strong neurotropism. ${ }^{48}$

The other three equid herpesviruses are classified in the Gammaherpesvirinae subfamily: EHV-2 and EHV-5 in the Percavirus genus, while EHV-7 (asinine herpesvirus 2, ASH-2) is currently listed as an unassigned species. ${ }^{47}$ A number of unclassified $\gamma$-EHVs have been identified in donkeys, and the names asinine herpesvirus 4 (ASH-4), asinine herpesvirus 5 (ASH-5), and asinine herpesvirus 6 (ASH-6) have been proposed. ${ }^{49,50}$

The horse is the natural host of EHV-1, EHV-2, EHV-3, EHV-4, and EHV-5, while the donkey hosts ASH-1 (EHV-6), ASH-2 (EHV-7), ASH-3 (EHV-8), ASH-4, ASH-5, and ASH-6. Additional $\gamma$-HVs have been identified in Namibian mountain zebras and in a Somali wild ass. ${ }^{51}$

EHV-2 and EHV-5 are the most well-known $\gamma$-HV of equids. Prior to the late 1980 s, EHV-2 was classified as a betaherpesvirus; at the time, it was not distinguished from EHV-5. ${ }^{3-5}$ Strong cross-reactivity exists between these viruses, making it difficult to distinguish these two virus infections on serological grounds. For this reason, general reference is made to $\gamma$-HV infections. ${ }^{52}$ Accordingly, molecular detection and typing have been used more frequently than serological tests to study these viruses. 


\section{Epidemiology of $\boldsymbol{\gamma}$-EHV infections}

EHV-2 and EHV-5 are believed to be endemic in horse populations worldwide. Various studies have reported a wide range of prevalence, ranging from $3 \%-10 \%{ }^{53,54}$ to $100 \%,{ }^{18,55}$ with a higher prevalence generally reported for EHV-2 than for EHV-5 infection..$^{27,56-58}$ These differences in prevalence are based on time of sampling, geographic location, population tested, assay type, specimen type, criteria used to define a sample as positive, and the sensitivity and specificity of the tests used. ${ }^{27,55,56,59,60}$ Moreover, detection of $\gamma$-HV infections may be underestimated in horse populations, especially where latent infection is present and viruses are not easily detected. ${ }^{44} \mathrm{An}$ age prevalence has been observed both for EHV-2 and EHV-5 infections, as is the case with other $\gamma$-HVs s. ${ }^{59,61-68}$ Horses kept in high-density environments were recognized to have a higher risk of infection. ${ }^{61}$ Nasal shedding of EHV-2 seems more common in the colder months of the year. ${ }^{69}$ Based on sequence divergence of the genome, the existence of geographically different strains has been hypothesized. ${ }^{22}$

Transmission occurs horizontally. Although these viruses do not appear to cross the placenta, their DNA has been detected in the placenta of an aborted fetus, associated with neonatal mortality, and in the uterus. ${ }^{42,69-73}$ In general, it could be said that these viruses have been isolated from a wide range of tissues/organs in the species they infect. . $8,69,74-76^{-1}$

The main strategy for survival of these viruses in the host population is latency that supervenes after primary infection. Both EHV-2 and EHV-5 infect lymphocytes, with B lymphocytes thought to represent a major site of EHV-2 persistence. ${ }^{9,26,77,78} \mathrm{EHV}-2$ is most frequently isolated from leukocytes and lymphoid tissue. ${ }^{79}$ Other recognized sites of latency are the peripheral and central nervous systems. ${ }^{75,79,80}$ Detection of EHV-2 DNA in the peripheral nervous system is of particular interest, given that the virus targets the upper respiratory tract and that the nasal epithelium is innervated by the maxillary branch of the trigeminal nerve, and the trigeminal ganglion may be a strategic site of latency of EHV-2. ${ }^{80}$ On the other hand, $\gamma$-HV affecting cattle and humans has also been demonstrated in the peripheral and central nervous systems. ${ }^{26,81-83}$

Potential sites of viral latency have not yet been identified for EHV-5, ${ }^{84}$ notwithstanding the fact that EHV-5 DNA has been demonstrated in alveolar macrophages. ${ }^{85}$

Viral antigens and replicating virus are not detected in latently infected animals. Accordingly, latent infection cannot be excluded in horses that are polymerase chain reaction-negative for replicating EHV-2 or EHV-5.9,44
Latent infections can be reactivated in the absence of clinical signs, for example, after administration of high doses of corticosteroids. ${ }^{26,75,79,86,87} \mathrm{In}$ light of this, detection of equine $\gamma$-HV may be a consequence of reactivation of latent infection following a clinical syndrome rather than the inciting cause of the clinical syndrome.

\section{EHV-2 infection Cycle of infection}

Early peri-partum infection with EHV-2 occurs in foals, ${ }^{7,18,62,88-92}$ even though these animals generally have high titers of maternally-derived antibodies. ${ }^{93} \mathrm{EHV}-2$ is most frequently transmitted horizontally to a newborn foal from its dam via the nasopharyngeal route or subsequently, through contact with other foals. ${ }^{18,19}$ Primary infection with EHV-2 can occur in foals as early as 25-30 days of age, although in the majority of cases, foals are infected at 2-4 months when maternal antibody titers are declining. . $^{718,60,90-94}$ The prevalence of infection at this age reaches $100 \%{ }^{18,60,90}$ Persistent infection is established with constant shedding. ${ }^{95}$ Foals shed higher viral loads than adult horses. ${ }^{7}$ The prevalence of infection seems to decline at 9 months, ${ }^{90}$ at a time when antibody levels increase. ${ }^{60,91,92}$ Periodic reactivation of latent infections can occur throughout the life of the horse, resulting in spread of infection within a population. However, infections in later life appear mostly to be asymptomatic. ${ }^{74,79,95}$ Seroconversion or an increase in antibody titers has been used to identify active infections. ${ }^{54,60,89-92}$ Antibody titers can fluctuate independently of the presence/absence of clinical signs. ${ }^{54,74}$ The level of serum/neutralizing antibodies seems to reflect the antigen load and is not necessarily indicative of protective immunity, as already reported in immunosuppressed humans with cytomegalovirus infection. ${ }^{78}$ Antibodies can be lifelong, ${ }^{62}$ and the virus can persist and be shed even in the presence of high antibody levels, probably due to genetic variation among the virus strains in circulation. ${ }^{71,90,92}$ Different strains of EHV-2 can infect the same animal. They may come from a variety of sources, including reactivation of a particular virus strain by the mare or by contact with different genotypes from other foals and horses. ${ }^{95}$ Genomic heterogeneity of EHV-2 may also be generated within a single host, and may be a consequence of maturation of the immune system in the foal. ${ }^{18-21,26,86,96}$ However, persistent infection with constant viral shedding seems less common than reinfection and reshedding. ${ }^{95}$ Genomic heterogeneity of the virus may account for frequent reinfections. ${ }^{26}$

EHV-2 has been detected often in immunocompetent hosts in the absence of signs of disease. . $^{18,22,26,54-58,60,62,66,69,74,88,93,97-105}$ 
Schlocker et al ${ }^{106}$ have hypothesized that EHV-2 behaves differently in foals than in adult horses. It could be that EHV-2 is not strictly cell-bound in foals and that it can be easily isolated from swab samples obtained from the upper respiratory tract and eyes, associated with mild cases of infection; on the other hand, the virus is strictly cell-bound in adult and older horses, being contained in macrophages and possibly lymphocytes. ${ }^{106}$

\section{Clinical signs}

Mild to severe chronic pharyngitis has been associated with EHV-2 infection of foals in both natural and experimental settings. ${ }^{107}$ In natural infection, pharyngitis with or without lymphadenopathy can also occur in association with other clinical signs of upper respiratory tract disease, including rhinitis and occasionally pyrexia associated with lymphocytosis. ${ }^{75,90,91,99,108}$ Continued shedding of EHV-2 into the nasopharynx was associated with progression of severity of the disease, leading to chronic pharyngitis that was characterized by ulcerative lesions with follicular hyperplasia but without overt clinical signs in two experimentally infected foals. ${ }^{107}$ The association of EHV-2 infection with clinical signs and a specific lymphocytic response is suggestive of an immunologically mediated disease similar to infectious mononucleosis caused by Epstein-Barr virus. ${ }^{108}$

EHV-2 has also been associated with many disease syndromes in older horses, although investigations of clinically normal, mature horses are less frequently documented than in foals. Experimental studies in horses older than 18 months of age have been less successful in reproducing clinical signs akin to those observed in foals. There are reports of a poor performance syndrome in racehorses related to infection with EHV-2, ${ }^{109}$ reminiscent of what is seen in cases of infectious mononucleosis in humans. Clinical signs associated with poor performance include general malaise, mild respiratory disease sometimes including a cough, chronic lymphoid follicular hyperplasia, swelling of regional head and neck lymph nodes, pharyngitis, anorexia, low-grade pyrexia, and respiratory signs, or persistent poor performance that does not respond to antibiotic therapy and affecting mostly younger horses. ${ }^{71,110} \mathrm{EHV}-2$ infection is also associated with neutrophilia and long-lasting airway inflammation. ${ }^{20}$

Although EHV-2 has been associated with conjunctivitis in horses of all ages, viral antigen has also been detected in the conjunctiva of clinically healthy horses. ${ }^{54,61,75,98,111-115}$ The cells that EHV-2 targets in the conjunctiva of healthy horses have been identified as histiocyte-like cells located in the submucosa, particularly Langerhans cells. ${ }^{98}$ The combined evidence from natural and experimental infections and the success of antiviral therapy in a cohort study would support a role for EHV-2 in the pathogenesis of keratoconjunctivitis in foals and adult horses, ${ }^{54,61,116}$ and yearlings following immunosuppressive doses of dexamethasone. ${ }^{75}$

Outbreaks of severe respiratory disease in association with EHV-2 infection have been reported in groups of horses in many countries, ${ }^{26,55,60,71,88-90,100,101,117,118}$ with foals aged 6-10 weeks developing the most severe clinical signs. ${ }^{89}$

The molecular detection of these viruses, often confirmed by immunohistochemistry, has identified them in association with a range of previously unidentified pathologies, including abortion, endometritis, dermatitis, granulomatous dermatitis, and oral and esophageal ulcers. ${ }^{42,69,70,72,119-121}$

\section{Coinfections associated with EHV-2 infection}

There have been occasional studies investigating the relationship with other herpesviral or bacterial infections. It has been proposed that EHV-2 may have a role in transactivation of EHV-1 and EHV-4 either alone or in association with EHV-5. ${ }^{42,67,68,70,73-75,84,110,121-128}$ That notwithstanding, the relevance of these findings is not well defined.

Association with bacterial infections has also been reported; EHV-2 may act as a possible "open door" for these infections. ${ }^{32,42,43,99,118}$ There is evidence that EHV-2 can be associated with outbreaks of bacterial infection of the lower respiratory tract resulting in pneumonia, frequently caused by Rhodococcus equi. Vaccination with EHV-2 with or without $R$. equi has been found to protect against R. equi pneumonia. ${ }^{43,129}$

\section{Immune response to EHV-2 infection}

There are very few studies on the nature of the immune response to EHV-2 infection, other than it includes a significant interferon-gamma response on the part of the host. $^{52,108}$

\section{EHV-5 infection Cycle of infection}

EHV-5 infection in foals occurs later than EHV-2. ${ }^{57,99,130}$ While detection of nasal shedding has been reported in foals as early as one month of age, ${ }^{7,18} \mathrm{EHV}-5$ infection is more prevalent at the time of weaning and postweaning. ${ }^{18,55,57,84,91,99,130} \mathrm{An}$ age-related prevalence of infection has been identified in younger horses, which would appear to be more susceptible to infection. ${ }^{59,61}$ Although the percentage of infected horses decreases with age, viral loads do not seem to vary 
significantly with age. ${ }^{68}$ Significant genomic variability exists among EHV-5 isolates as it does in the case of EHV-2;26,131 however, it seems less evident than with EHV-2. 8,18,21,22,26,113,132 EHV-5 has been regularly isolated and detected in healthy horses. . $^{8,18,22,26,27,55,56,58,66,84,133}$

\section{Clinical signs}

EHV-5 has been associated with a number of different pathological conditions. Poor performance syndrome and respiratory signs in yearlings and adult horses have been reported. $22,53,66,84,99,100,118,134,135$ The role of the virus in ocular disease has not been defined. ${ }^{61,113,115} \mathrm{~A}$ case of dermatitis, similar to herpes-associated erythema multiforme in humans, has been described in association with EHV-5. ${ }^{136}$ Moreover, EHV-5 DNA has been found in uterine flushings, ${ }^{121}$ aborted fetuses, and cases of neonatal mortality. ${ }^{42,70}$ Also, EHV-5 has been associated with a systemic granulomatous disease in a warmblood gelding with severe oral and esophageal ulceration together with spleen and bone marrow involvement. ${ }^{137}$ More recently, a possible link has been suggested between EHV-5 infection and hematological disorders. Pancytopenia ${ }^{138}$ and chronic T-cell leukemia or lymphoma ${ }^{14-17}$ have been reported. EHV-5 was detected in bone marrow aspirate samples by polymerase chain reaction and typical viral inclusions were observed in infected cells. ${ }^{14,138}$ Similar lesions have been reported in humans with Epstein-Barr infection. ${ }^{139,140}$ There is also the occasional detection or isolation of EHV-5 as well as other viruses or bacteria. ${ }^{42,53,67,68,70,73,84,121,126,134,135}$

\section{Equine multinodular pulmonary fibrosis}

The most relevant association, discovered several years ago, is between EHV-5 and a characteristic progressive interstitial pulmonary fibrosis, with a nodular appearance, now termed equine multinodular pulmonary fibrosis (EMPF). EMPF was proposed as a distinct pathological entity in 2007..$^{85}$ Since then, sporadic occurrences have been diagnosed worldwide. ${ }^{14,17,85,138,141-158}$ On histological examination, there is marked interstitial fibrosis, often with preservation of an "alveolar-like" architecture, lined with cuboidal epithelial cells. The airways contain primarily neutrophils and macrophages, including some macrophages with eosinophilic inclusion bodies in which EHV-5 DNA was identified by in situ hybridization. ${ }^{85,158}$ Recently, EMPF has also been reproduced by experimental infection in three of six clinically normal horses after inoculation with two strains of EHV-5 previously isolated from EMPF cases. ${ }^{44}$ Interestingly, the same horses were found to be infected not only with the challenge strain but also with other wild strains of EHV-5.
Based on this study, the route of EHV-5 infection (obtained via endoscopy in the accessory lung lobe) has been hypothesized as possibly having a role in determining the pathogenesis of the disease caused by a virus usually considered nonpathogenic in the natural host. The other hypothesis is that only particular strains of EHV-5 can cause EMPF. ${ }^{44}$ Moreover, another report found a proportional quantitative relationship between EHV-5 load and severity of EMPF lesions. This was based on detection of EHV-5 DNA by quantitative real-time polymerase chain reaction in bronchoalveolar lavage fluid and post mortem tissues, especially lungs, where the highest loads of EHV-5 were detected in the most severe EMPF lesions. ${ }^{146}$ EHV-5 has been consistently identified in all cases of EMPF, alone or in association with EHV-2 or AHV-5, although no systematic research of the possible role of these other $\gamma$-HVs was undertaken in the different studies. ${ }^{85,138,142,143,146,148,158}$ At present, however, it is not possible to unequivocally state whether EHV-5 causes EMPF, or whether the environment in the lung caused by EMPF results in an increase in EHV-5 loads. Moreover, the successful response reported after antiviral treatment with acyclovir ${ }^{156}$ and valacyclovir ${ }^{14}$ in some cases of EMPF would not lend support to the causal role of EHV-5, based on the fact that numerous other cases did not survive following antiviral therapy ${ }^{138,146,158}$ and some may spontaneously recover from the disease. ${ }^{152,158}$

There is no evidence of natural transmission of EMPF; however, it is worth noting that the majority of reported cases were housed with other horses that did not develop signs of disease. No epidemiological investigations have been conducted to date in reported cases of the disease. ${ }^{159,160}$ Accordingly, no breed or other risk or predisposing factors have yet been identified.

Furthermore, the pathogenesis of EMPF is yet to be defined. The majority of cases of the disease have been in middle-aged and older horses, but it should also be noted that EMPF has been diagnosed in horses younger than 2 years. ${ }^{85,141,147,149,161}$ However, the disease is more severe in older horses, ${ }^{155}$ akin to what has been reported with other $\gamma$-HVs, like murine $\gamma$-herpesvirus $68 .{ }^{162}$

Horses with EMPF generally have a history of weight loss, poor condition, exercise intolerance, inappetence, no improvement after treatment for heaves or infectious bronchopneumonia, and progression of clinical signs prior to confirmation of a diagnosis of EMPF. Variable hyperthermia, wasting, and tachycardia are observed on physical examination. The respiratory signs are generally severe and remittent, accompanied by tachypnea and dyspnea, with significant arterial hypoxemia in some cases. Thoracic auscultation is usually 
abnormal, with wheezes and crackles commonly reported both with and without rebreathing examination. Neurological signs, ocular signs, oral inflammation, and ulcerations have been occasionally observed. ${ }^{138,142,143,149,152}$ Moreover, ocular signs have also developed during treatment. ${ }^{147}$

Hyperfibrinoginemia, leucocytosis, neutrophilia, monocytosis, anemia, pancytopenia, and hypoxemia have frequently been listed in recorded cases. Hypoalbuminemia may also occur in some cases. ${ }^{138,160}$

Multiple organ involvement, including glomerular nephritis, hepatic fibrosis, hepatic parenchymal destruction, and myocardial fibrosis have been described. ${ }^{142,146,149,152}$ Cases of EMPF associated with leukemia or lymphoma have been reported. ${ }^{14,17}$ Hypertrophic osteopathy secondary to EMPF has been recorded, even where EHV-5 was not detected. ${ }^{147}$ Diagnosis of EMPF is generally made late in the clinical course of the disease, because the clinical signs are initially nonspecific. Radiographic findings are fairly typical and are characterized by a severe, diffuse, nodular interstitial pattern that is either uniformly distributed or evident primarily in the mid-ventral to cranio-ventral lung lobes. Ultrasonographic examination reveals a bilateral, diffuse roughening of the pleural surface and, as the disease progresses, the existence of multiple superficial discrete nodules of varying size. On cytological examination, transtracheal aspirates and/or bronchoalveolar lavage fluid are characterized by a predominance of nondegenerate neutrophils with fewer macrophages and lymphocytes, with eosinophilic intranuclear inclusion bodies occasionally found in macrophages, suggesting a viral etiology. Bronchoalveolar lavage samples from EMPF cases are almost uniformly polymerase chain reaction-positive for EHV-5 in the cases reported to date, and a quantitative relationship has been found between this type of sample and EHV-5 load. ${ }^{146,160}$ However, the presence of EHV-5 in bronchoalveolar lavage fluid is not currently considered sufficient evidence on which to base a diagnosis of EMPF in the absence of characteristic clinical signs, radiographic/ultrasonographic findings, and especially lung histopathology. ${ }^{85,137,155,159,160}$ The gold standard for ante mortem diagnosis of EMPF is based on histopathological evaluation of lung sections obtained by percutaneous, ultrasound-guided biopsy procedures, and demonstration of characteristic histological lesions of EMPF. ${ }^{160}$ Microbiological analyses are important to rule out fungal, bacterial, or silicate-induced granulomatous interstitial lung disease.

Considering its as yet undefined etiology, the treatment of EMPF is not definitive and largely symptomatic. ${ }^{160,161}$ Corticosteroids are advocated to suppress pulmonary inflammation by inhibiting the synthesis of inflammatory cytokines and mediators that promote fibrosis and cellular infiltration. Antimicrobial therapy is generally recommended to prevent bacterial superinfection. ${ }^{160}$ Use of acyclovir or valaciclovir (an acyclovir prodrug with greater bioavailability if administered orally) is speculative, because the pathogenic role of EHV-5 is not fully proven and the susceptibility of equine $\gamma$-HV to these antivirals is unknown. That notwithstanding, antiviral treatment has had a beneficial effect in some cases. ${ }^{160}$ Additional treatment considerations include administration of parenteral fluids if the horse is dehydrated, and moving the horse to a cool, well ventilated environment. Intranasal insufflation of humidified oxygen is indicated in hypoxemic horses. Other medications, including nonsteroidal anti-inflammatory medications, can be used for management of pain and fever.

The prognosis in confirmed cases of EMPF is currently poor. The majority of affected horses either die or have to be euthanized due to poor response to treatment. Nevertheless, resolution of cases of the disease has also been described with $^{150,158}$ or without ${ }^{152}$ ongoing treatment. It also appears that response to treatment is better in horses diagnosed early in the clinical course or in mildly affected horses displaying a low level of tachypnea, while advanced cases appear refractory to treatment. Duration of treatment in horses with a diagnosis of EMPF should last at least 6 weeks, providing adequate time for the anti-inflammatory and antiviral therapy to work. ${ }^{160}$

\section{Immune response to EHV-5 infection}

At the moment, there have been no studies aimed at characterizing the immune response against EHV-5 infection in healthy horses or in cases of EMPF.

\section{Asinine $\boldsymbol{\gamma}-\mathrm{HV}$ infection}

More limited information is available on AHV than on any other EHV of horses. The majority of what has been published on AHV is based on studies of short genetic sequences (generally less than 200 base pairs). Careful consideration should be placed on phylogenetic findings, because mistakes in viral classification are possible due to the high genomic heterogeneity of these viruses. ${ }^{163,164}$ It is possible that other $\gamma$-EHVs exist. ${ }^{163}$

AHV-2 (EHV-7) was isolated for the first time in 1988 from a healthy donkey. ${ }^{6}$ Subsequently, AHV-2 DNA was detected in 9/114 (7.9\%) nasal swabs and 2/96 whole blood samples from mules and 1/13 (7.7\%) nasal swabs and 2/96 whole blood samples from donkeys participating in a large 
show in the USA. ${ }^{163}$ This study found the prevalence was lower compared with $\gamma$-HV infection in horses. However, this prevalence could be an underestimate due to limited information about the known genomic heterogeneity of the viruses which could have limited sensitivity in the tests used to diagnose the infection. ${ }^{163}$

AHV-4, AHV-5, and AHV-6 have been associated with interstitial pneumonia in donkeys, characterized by marked syncytial cell formation. Affected individuals present clinically with acute and often fatal respiratory disease. ${ }^{49,50} \mathrm{In}$ particular, Kleiboeker et $\mathrm{al}^{49}$ identified eleven donkeys with pulmonary lesions positive for $\gamma$-HV DNA (AHV-4 in five cases and AHV-5 in six cases), whereas six controls from the same farms, none of which had pulmonary lesions, were negative for $\gamma$-HV DNA. The positive donkeys were from five different premises without previous cross-contact and two of the herds had a history of recent outbreaks of fatal respiratory disease in adult donkeys. However, the clinical relevance of these viruses has not yet been established. In contrast, another study did not find differences in the distribution of AHV-4 or AHV-5 in the lungs of donkeys with pulmonary fibrosis $(n=4)$ and in controls $(n=4)$, identifying six $\gamma$-HV DNA-positive cases; however, no further details were provided in this report. ${ }^{46}$

AHV-5 was also reported in association with a case of neurological disease in a donkey with depression, mild paresis, and ataxia, that eventually recovered. ${ }^{164}$

Detection of AHV-5 was reported also in horses, in which it was associated with pyogranulomatous pneumonia and signs of EMPF. The virus has also been detected in healthy animals. ${ }^{53,110,114,148,165}$ In some of these cases, the virus was associated with EHV-5..$^{53,110,114,148}$ The virus was detected in the blood, nasal swabs, and conjunctiva of healthy horses. ${ }^{114}$ No previous contact with donkeys was reported in some of these reports, ${ }^{114,148}$ whereas it had been in other cases. ${ }^{165} \mathrm{In}$ the case reported by De Witte et a ${ }^{165}$ of pyogranulomatous pneumonia in a pregnant mare, molecular investigation of $\gamma$-HV DNA was performed on nasal swabs of two donkeys and a Quarter horse gelding, cohorts to the case in question, and all the animals, including the gelding, were found to be positive for AHV-5. It is not clear why the mare developed clinical disease whereas the donkeys and the gelding on the same farm remained healthy. Perhaps another pathogen or the stress associated with pregnancy could have had a role in the pathogenesis of the pneumonia.

A suspected role for $\gamma$-HV was hypothesized also in a case of pulmonary angiocentric lymphoma in a donkey. In this case, no $\gamma$-HV DNA was detected in the tissues of the animal.
However, the virus was detected on the farm from which the case originated. ${ }^{13}$

\section{Conclusion}

The ubiquitousness of $\gamma-\mathrm{HV}$ in equid populations and their natural capacity to establish persistent, latent infections continue to make it difficult to assign a causal role for these viruses in the etiology of certain clinical syndromes or to identify an appropriate means of therapy. Identification of the viruses in clinical samples alone is not enough to link them with disease. Greater understanding of the pathogenesis of these diseases, especially in cases of respiratory infection, would enhance our ability to diagnose such diseases and more accurately predict the outcome. It would also limit the use of inappropriate treatments, like antimicrobial therapy, in the present era of antibiotic resistance.

One approach to furthering our understanding of the role of these viruses in disease could be to focus future research efforts on coinfections associated with $\gamma$-HV, based on the potential of these viruses to modulate host immune responses, and determine whether their role is one of primary pathogens or as conditioning agents predisposing to secondary infections. Characterization of the immune response to these infections both in healthy and in ill equids should help in elucidating possible pathological patterns. The study of these infections in non-natural hosts should also be investigated.

Moreover, parallels between the $\gamma$-EHV and other $\gamma$-HVs, especially Epstein-Barr virus in humans, could be useful in helping to define their pathogenic potential and identify risk factors associated with disease as well as develop animal models of disease, especially for pulmonary fibrosis. ${ }^{45,46}$

Another aspect that warrants investigation is the need to develop a database of information based on phylogenetic studies of the sequences of viruses like EHV-5 or AHVs associated with pulmonary lesions, for which only limited data currently exist. Such information might enable us to identify possible clusters based on specific pathologies, like EMPF in horses or pneumonia in donkeys. Further virological and epidemiological studies are needed to clarify all these unanswered questions and to improve our knowledge of the role and involvement of these agents in different equine pathological conditions.

\section{Disclosure}

The authors report no conflicts of interest in the present work.

\section{References}

1. Plummer G, Waterson AP. Equine herpes viruses. Virology. 1963;19: 412-416. 
2. Plummer G, Bowling $\mathrm{CP}$, Goodheart $\mathrm{CR}$. Comparison of four horse herpesviruses. J Virol. 1969;4:738-741.

3. Browning GF, Studdert MJ. Genomic heterogeneity of equine betaherpesviruses. J Gen Virol. 1987;68:1441-1447.

4. Agius CT, Nagesha HS, Studdert MJ. Equine herpesvirus 5: comparisons with EHV2 (equine cytomegalovirus), cloning, and mapping of a new equine herpesvirus with a novel genome structure. Virology. 1992;191:176-186.

5. Telford EA, Studdert MJ, Agius CT, Watson MS, Aird HC, Davison AJ. Equine herpesviruses 2 and 5 are gamma-herpesviruses. Virology. 1993;195:492-499.

6. Browning GF, Ficorilli N, Studdert MJ. Asinine herpesvirus genomes: comparison with those of the equine herpesviruses. Arch Virol. 1988;101:183-190.

7. Hartley CA, Dynon KJ, Mekuria ZH, El-Hage CM, Holloway SA, Gilkerson JR. Equine gammaherpesviruses: perfect parasites? Vet Microbiol. 2013;167:86-92.

8. Thorsteinsdóttir L, Torfason EG, Torsteinsdóttir S, Svansson V. Isolation and partial sequencing of equid herpesvirus 5 from a horse in Iceland. J Vet Diagn Invest. 2010;22:420-423.

9. Drummer HE, Reubel GH, Studdert MJ. Equine gammaherpesvirus 2 (EHV2) is latent in B lymphocytes. Arch Virol. 1996;141:495-504.

10. Ackermann M. Pathogenesis of gammaherpesvirus infections. Vet Microbiol. 2006;113:211-222.

11. Williams KJ. Gammaherpesviruses and pulmonary fibrosis: evidence from humans, horses, and rodents. Vet Pathol. 2014;51:372-384.

12. Barton ES, White DW, Cathelyn JS, et al. Herpesvirus latency confers symbiotic protection from bacterial infection. Nature. 2007;447: 326-329.

13. Du Toit N, Genovese LM, Dalziel RG, Smith SH. Pulmonary angiocentric lymphoma (lymphomatoid granulomatosis) in a donkey. J Comp Pathol. 2012;146:24-29.

14. Schwarz B, Gruber A, Benetka V, et al. Concurrent T cell leukaemia and equine multinodular pulmonary fibrosis in a Hanoverian warmblood mare. Equine Vet Educ. 2012;24:187-192.

15. Vander Werf K, Davis E. Disease remission in a horse with EHV-5associated lymphoma. J Vet Intern Med. 2013;27:387-389.

16. Vander Werf KA, Davis EG, Janardhan K, et al. Identification of equine herpesvirus 5 in horses with lymphoma. J Equine Vet Sci. 2014;34: 738-741.

17. Bawa B, Werf KV, Beard L, Davis E, Andrews G, Almes K. Equine multinodular pulmonary fibrosis and lymphoma in a horse associated with equine herpesvirus-5. J Equine Vet Sci. 2014;34:694-700.

18. Bell SA, Balasuriya UB, Gardner IA, et al. Temporal detection of equine herpesvirus infections of a cohort of mares and their foals. Vet Microbiol. 2006;116:249-257.

19. Brault SA, Bird BH, Balasuriya UB, MacLachlan NJ. Genetic heterogeneity and variation in viral load during equid herpesvirus- 2 infection of foals. Vet Microbiol. 2011;147:253-261.

20. Fortier G, Richard E, Hue E, et al. Long-lasting airway inflammation associated with equid herpesvirus-2 in experimentally challenged horses. Vet J. 2013;197:492-495.

21. Thorsteinsdóttir L, Torfason EG, Torsteinsdóttir S, Svansson V. Genetic diversity of equine gammaherpesviruses (gamma-EHV) and isolation of a syncytium forming EHV-2 strain from a horse in Iceland. Res Vet Sci. 2013;94:170-177.

22. Ataseven VS, Bilge-Dagalp S, Oguzoglu TC, Karapinar Z, Güzel M, Tan MT. Detection and sequence analysis of equine gammaherpesviruses from horses with respiratory tract disease in Turkey. Transbound Emerg Dis. 2010;57:271-276.

23. Sitki-Green D, Covington M, Raab-Traub N. Compartmentalization and transmission of multiple Epstein-Barr virus strains in asymptomatic carriers. J Virol. 2003;77:1840-1847.

24. Holloway SA, Lindquester GJ, Studdert MJ, Drummer HE. Analysis of equine herpesvirus 2 strain variation using monoclonal antibodies to glycoprotein B. Arch Virol. 2000;145:1699-1713.
25. Sharp EL, Farrell HE, Borchers K, Holmes EC, Davis-Poynter NJ. Sequence analysis of the equid herpesvirus 2 chemokine receptor homologues E1, ORF74 and E6 demonstrates high sequence divergence between field isolates. J Gen Virol. 2007;88:2450-2462.

26. Fortier G, van Erck E, Pronost $\mathrm{S}$, et al. Equine gammaherpesviruses: pathogenesis, epidemiology and diagnosis. Vet J. 2010;186:148-156.

27. Franchini M, Akens M, Bracher V, von Fellenberg R. Characterisation of gamma herpesviruses in the horse by PCR. Virology. 1997;238: $8-13$.

28. Plummer G, Goodheart CR, Studdert MJ. Equine herpesviruses: antigenic relationships and deoxyribonucleic acid densities. Infect Immun. 1973;8:621-627.

29. Telford EA, Watson MS, Aird HC, Perry J, Davison AJ. The DNA sequence of equine herpesvirus 2. J Mol Biol. 1995;249:520-528.

30. Brackmann J. The equine herpesvirus type 2 (EHV-2) interleukin-10 (IL10) homologue: activity during acute and latent infection with special consideration on gene expression in vivo and in vitro. Das Interleukin. 2005;10. http://www.diss.fu-berlin.de/diss/servlets/MCRFileNodeServlet/FUDISS_derivate_000000001926/00_dblim.pdf?hosts=. Accessed February 23, 2015.

31. Camarda G, Spinetti G, Bernardini G, et al. The equine herpesvirus 2 E1 open reading frame encodes a functional chemokine receptor. J Virol. 1999;73:9843-9848.

32. Dunowska M, Meers J, Johnson RD, Wilks CR. Influence of equine herpesvirus type 2 infection on monocyte chemoattractant protein 1 gene transcription in equine blood mononuclear cells. Res Vet Sci. 2001;71: 111-113.

33. Thome M, Martinon F, Hofmann K, et al. Equine herpesvirus-2 E10 gene product, but not its cellular homologue, activates NF-kappa B transcription factor and c-Jun N-terminal kinase. J Biol Chem. 1999;274: 9962-9968.

34. Ahuja SK, Gao JL, Murphy PM. Chemokine receptors and molecular mimicry. Immunol Today. 1994;15:281-287.

35. Davis-Poynter NJ, Farrell HE. Masters of deception: a review of herpesvirus immune evasion strategies. Immunol Cell Biol. 1996;74: $513-522$.

36. Fu ZF, Robinson AJ, Horner GW, Dickinson LG, Grimmett JB, Marshall RB. Respiratory disease in foals and the epizootiology of equine herpesvirus type 2 infection. $N$ Z Vet J. 1986;34:152-155.

37. Welchman Dde B, Verkuijl AM, Pepper WJ, et al. Association of gammaherpesviruses and bacteria with clinical metritis in a dairy herd. Vet Rec. 2012;170:207.

38. Cardenas I, Mor G, Aldo P, et al. Placental viral infection sensitizes to endotoxin-induced pre-term labor: a double hit hypothesis. $\mathrm{Am} \mathrm{J}$ Reprod Immunol. 2011;65:110-117.

39. Racicot K, Cardenas I, Wunsche V, et al. Viral infection of the pregnant cervix predisposes to ascending bacterial infection. JImmunol. 2013;191: 934-941.

40. Donofrio G, Cavirani S, van Santen V, et al. Potential secondary pathogenic role for bovine herpesvirus 4. J Clin Microbiol. 2005;43: 3421-3426.

41. Donofrio G, Cavirani S, van Santen V, Flammini CF. Bacterial infection of endometrial stromal cells influences bovine herpesvirus 4 immediate early gene activation: a new insight into bacterial and viral interaction for uterine disease. Reproduction. 2008;136:361-366.

42. Marenzoni ML, Bietta A, Lepri E, et al. Role of equine herpesviruses as co-infecting agents in cases of abortion, placental disease and neonatal foal mortality. Vet Res Commun. 2013;37:311-317.

43. Nordengrahn A, Rusvai M, Merza M, Ekström J, Morein B, Belák S. Equine herpesvirus type 2 (EHV-2) as a predisposing factor for Rhodococcus equi pneumonia in foals: prevention of the bifactorial disease with EHV-2 immunostimulating complexes. Vet Microbiol. 1996;51: $55-68$.

44. Williams KJ, Robinson NE, Lim A, et al. Experimental induction of pulmonary fibrosis in horses with the gammaherpesvirus equine herpesvirus 5. PLoS One. 2013;8:e77754. 
45. Vannella KM, Moore BB. Viruses as co-factors for the initiation or exacerbation of lung fibrosis. Fibrogenesis Tissue Repair. 2008;1:2.

46. Miele A, Dhaliwal K, Du Toit N, et al. Chronic pleuropulmonary fibrosis and elastosis of aged donkeys: similarities to human pleuroparenchymal fibroelastosis. Chest. 2014;145:1325-1332.

47. Davison AJ, Eberle R, Ehlers B, et al. The order Herpesvirales. Arch Virol. 2009;154:171-177.

48. Fukushi H, Yamaguchi T, Yamada S. Complete genome sequence of equine herpesvirus type 9. J Virol. 2012;86:13822.

49. Kleiboeker SB, Schommer SK, Johnson PJ, et al. Association of two newly recognized herpesviruses with interstitial pneumonia in donkeys (Equus asinus). $J$ Vet Diagn Invest. 2002;14: 273-280

50. Kleiboeker SB, Turnquist SE, Johnson PJ, Kreeger JM. Detection and nucleotide sequencing of a DNA-packaging protein gene of equine gammaherpesviruses. J Vet Diagn Invest. 2004;16:67-74.

51. Ehlers B, Borchers K, Grund C, Frölich K, Ludwig H, Buhk HJ. Detection of new DNA polymerase genes of known and potentially novel herpesviruses by PCR with degenerate and deoxyinosinesubstituted primers. Virus Genes. 1999;18:211-220.

52. Svansson V, Roelse M, Olafsdóttir G, Thorsteinsdóttir L, Torfason EG, Torsteinsdóttir S. Immune response against equine gammaherpesvirus in Icelandic horses. Vet Microbiol. 2009;137:363-368.

53. Fortier G, Pronost S, Miszczak F, et al. Identification of equid herpesvirus- 5 in respiratory liquids: a retrospective study of 785 samples taken in 2006-2007. Vet J. 2009;182:346-348.

54. Kershaw O, von Oppen T, Glitz F, Deegen E, Ludwig H, Borchers K. Detection of equine herpesvirus type $2(\mathrm{EHV}-2)$ in horses with keratoconjunctivitis. Virus Res. 2001;80:93-99.

55. Wang L, Raidal SL, Pizzirani A, Wilcox GE. Detection of respiratory herpesviruses in foals and adult horses determined by nested multiplex PCR. Vet Microbiol. 2007;121:18-28.

56. Reubel GH, Crabb BS, Studdert MJ. Diagnosis of equine gammaherpesvirus 2 and 5 infections by polymerase chain reaction. Arch Virol. 1995;140:1049-1060.

57. Nordengrahn A, Merza M, Ros C, et al. Prevalence of equine herpesvirus types 2 and 5 in horse populations by using type-specific PCR assays Vet Res. 2002;33:251-259.

58. Torfason EG, Thorsteinsdottir L, Torsteinsdottir S, Svansson V. Study of equid herpesviruses 2 and 5 in Iceland with a type-specific polymerase chain reaction. Res Vet Sci. 2008;85:605-611.

59. Marenzoni ML, Coppola G, Maranesi M, et al. Age-dependent prevalence of equid herpesvirus 5 infection. Vet Res Commun. 2010;34: 703-708.

60. Marenzoni ML, Passamonti F, Cordioli P, et al. [Clinical and diagnostic features of equine herpesvirus type 2 (EHV-2) infection in 15 foals]. Ippologia. 2007;18:37-41. Italian.

61. Rushton JO, Kolodziejek J, Tichy A, Nowotny N, Nell B. Clinical course of o phthalmic findings and potential influence factors of herpesvirus infections: 18 month follow-up of a closed herd of Lipizzaners. PLoS One. 2013;8:e79888.

62. Craig MI, Barrandeguy ME, Fernandez FM. Equine herpesvirus 2 (EHV-2) infection in thoroughbred horses in Argentina. BMC Vet Res. 2005;1.

63. Buckles EL, Lowenstine LJ, DeLong RL, et al. Age-prevalence of otarine herpesvirus-1, a tumor-associated virus, and possibility of its sexual transmission in California sea lions. Vet Microbiol. 2007;120: $1-8$.

64. Ptaschinski C, Rochford R. Infection of neonates with murine gammaherpesvirus 68 results in enhanced viral persistence in lungs and absence of infectious mononucleosis syndrome. J Gen Virol. 2008;89: 1114-1121.

65. Cho HJ, Kim S, Kwak SE, et al. Age-dependent pathogenesis of murine gammaherpesvirus 68 infection of the central nervous system. Mol Cells. 2009;27:105-111.
66. Akkutay AZ, Osterrieder N, Damiani A, Tischer BK, Borchers K, Alkan F. Prevalence of equine gammaherpesviruses on breeding farms in Turkey and development of a TaqMan MGB real-time PCR to detect equine herpesvirus 5 (EHV-5). Arch Virol. 2014;159: 2989-2995.

67. Pusterla N, Mapes S, Wademan C, White A, Hodzic E. Investigation of the role of lesser characterised respiratory viruses associated with upper respiratory tract infections in horses. Vet Rec. 2013;172:315.

68. Hue ES, Fortier GD, Fortier CI, et al. Detection and quantitation of equid gammaherpesviruses (EHV-2, EHV-5) in nasal swabs using an accredited standardised quantitative PCR method. J Virol Methods. 2014;198:18-25

69. Browning GF, Studdert MJ. Equine herpesvirus 2 (Equine cytomegalovirus). Vet Bull. 1988;58:775-790.

70. Léon A, Fortier G, Fortier C, et al. Detection of equine herpesviruses in aborted foetuses by consensus PCR. Vet Microbiol. 2008;126:20-29.

71. Studdert MJ. Comparative aspects of equine herpesviruses. Cornell Vet. 1974;64:94-122.

72. Galosi CM, Cid de la Paz V, Fernandez LC, et al. Isolation of equine herpesvirus-2 from the lung of an aborted fetus. $J$ Vet Diagn Invest. 2005; $17: 500-502$

73. Smith KL, Allen GP, Branscum AJ, et al. The increased prevalence of neuropathogenic strains of EHV-1 in equine abortions. Vet Microbiol. 2010;141:5-11.

74. Borchers K, Wolfinger U, Goltz M, Broll H, Ludwig H. Distribution and relevance of equine herpesvirus type 2 (EHV-2) infections. Arch Virol. 1997;142:917-928.

75. Borchers K, Wolfinger U, Ludwig H, et al. Virological and molecular biological investigations into equine herpes virus type 2 (EHV-2) experimental infections. Virus Res. 1998;55:101-106.

76. Rizvi SM, Slater JD, Slade AJ, Field HJ. Transmission of equine herpesvirus 2 to the mouse: characterization of a new laboratory infection model. J Gen Virol. 1997;78:1119-1124.

77. Agius CT, Crabb BS, Telford EA, Davison AJ, Studdert MJ. Comparative studies of the structural proteins and glycoproteins of equine herpesviruses 2 and 5. J Gen Virol. 1994;75 Pt 10:2707-2717.

78. Gleeson LJ, Coggins L. Equine herpesvirus type 2: cell-virus relationship during persistent cell-associated viremia. Am J Vet Res. 1985;46: 19-23.

79. Edington N, Welch HM, Griffiths L. The prevalence of latent equid herpesviruses in the tissues of 40 abattoir horses. Equine Vet J. 1994;26: 140-142.

80. Rizvi SM, Slater JD, Wolfinger U, Borchers K, Field HJ, Slade AJ. Detection and distribution of equine herpesvirus 2 DNA in the central and peripheral nervous systems of ponies. J Gen Virol. 1997;78: 1115-1118.

81. Baumann RP, Sullivan DC, Staczek J, O'Callaghan DJ. Genetic relatedness and colinearity of genomes of equine herpesvirus types 1 and 3 . J Virol. 1986;57:816-825.

82. Borchers K, Wolfinger U, Ludwig H. Latency-associated transcripts of equine herpesvirus type 4 in trigeminal ganglia of naturally infected horses. J Gen Virol. 1999;80:2165-2171.

83. Hughes AL. Origin and evolution of viral interleukin-10 and other DNA virus genes with vertebrate homologues. J Mol Evol. 2002;54: 90-101.

84. Dunowska M, Meers J, Wilks CR. Isolation of equine herpesvirus type 5 in New Zealand. N Z Vet J. 1999;47:44-46.

85. Williams KJ, Maes R, Del Piero F, et al. Equine multinodular pulmonary fibrosis: a newly recognized herpesvirus-associated fibrotic lung disease. Vet Pathol. 2007;44:849-862.

86. Browning GF, Studdert MJ. Physical mapping of the genomic heterogeneity of isolates of equine herpesvirus 2 (equine cytomegalovirus). Arch Virol. 1989;104:87-94.

87. Gibson JS, Slater JD, Awan AR, Field HJ. Pathogenesis of equine herpesvirus- 1 in specific pathogen-free foals: primary and secondary infections and reactivation. Arch Virol. 1992;123:351-366. 
88. Turner AJ, Studdert MJ. Equine herpesviruses. 3. Isolation and epizootiology of slowly cytopathic viruses and the serological incidence of equine rhinopneumonitis. Aust Vet J. 1970;46:581-586.

89. Pálfi V, Belák S, Molnár T. Isolation of equine herpesvirus type 2 from foals, showing respiratory symptoms. Zentralbl Veterinarmed $B$. 1978;25:165-167.

90. Fu ZF, Denby L, Lien DH, Robinson AJ. An enzyme-linked immunosorbent assay (ELISA) for measurement of antibodies against equine herpesvirus 2 in equine sera. Acta Virol. 1987;31:468-474.

91. Murray MJ, Eichorn ES, Dubovi EJ, Ley WB, Cavey DM. Equine herpesvirus type 2: prevalence and seroepidemiology in foals. Equine Vet J. 1996;28:432-436.

92. Nordengrahn A, Klin geborn B, Lindholm A, Merza M. The use of a neutralizing monoclonal antibody to detect infections of equine herpesvirus type 2 (EHV-2). J Vet Diagn Invest. 2001;13:389-393.

93. Wilks CR, Studdert MJ. Equine herpesviruses. 5. Epizootiology of slowly cytopathic viruses in foals. Aust Vet J. 1974;50:438-442.

94. Dunowska M, Howe L, Hanlon D, Stevenson M. Kinetics of equid herpesvirus type 2 infections in a group of thoroughbred foals. Vet Microbiol. 2011;152:176-180.

95. Browning GF, Studdert MJ. Epidemiology of equine herpesvirus 2 (equine cytomegalovirus). J Clin Microbiol. 1987;25:13-16.

96. Ruszczyk A. [Genomic heterogeneity of EHV-2 strains isolated from horses in Poland]. Med Weter. 2003;59:620-622. Polish.

97. Bell SA, Balasuriya UB, Nordhausen RW, MacLachlan NJ. Isolation of equine herpesvirus-5 from blood mononuclear cells of a gelding. J Vet Diagn Invest. 2006;18:472-475.

98. Borchers K, Ebert M, Fetsch A, Hammond T, Sterner-Kock A. Prevalence of equine herpesvirus type 2 (EHV-2) DNA in ocular swabs and its cell tropism in equine conjunctiva. Vet Microbiol. 2006;118: 260-266.

99. Dunowska M, Wilks CR, Studdert MJ, Meers J. Equine respiratory viruses in foals in New Zealand. $N$ Z Vet J. 2002;50:140-147.

100. Dynon K, Black WD, Ficorilli N, Hartley CA, Studdert MJ. Detection of viruses in nasal swab samples from horses with acute, febrile, respiratory disease using virus isolation, polymerase chain reaction and serology. Aust Vet J. 2007;85:46-50.

101. Ruszczyk A, Cywinska A, Banbura MW. Equine herpes virus 2 infection in horse populations in Poland. Acta Virol. 2004;48:189-192.

102. Banbura MW, Witkowski L, Chmielewska A, Tucholska A, Rzewuska M, Ruszczyk A. [Mixed infections of equine herpes virus types 1 and 2 (EHV-1 and EHV-2)]. Med Weter. 2006;62:1071-1072. Polish.

103. Chabchoub A, Pronost S, Abidi N, Legrand L, Fortier G. [Frequency of the equine herpes virus type 2 in equines with chronic respiratory diseases in Tunisia]. Rev Med Vet. 2010;161:564-569. French.

104. Amer HM, Shaltout AK, El-Sabagh IM, El-Sanousi AA, Shalaby MA. Prevalence of equine herpes viruses 1,2 and 4 in Arabian horse population in Egypt. Afr J Microbiol Res. 2011;5:4805-4811.

105. Borchers K, Frolich K, Ludwig H. Detection of equine herpesvirus types 2 and 5 (EHV-2 and EHV-5) in Przewalski's wild horses. Arch Virol. 1999;144:771-780.

106. Schlocker N, Gerber-Bretscher R, von Fellenberg R. Equine herpesvirus 2 in pulmonary macrophages of horses. Am J Vet Res. 1995;56: 749-754.

107. Blakeslee JR Jr, Olsen RG, McAllister ES, Fassbender J, Dennis R. Evidence of respiratory tract infection induced by equine herpesvirus, type 2, in the horse. Can J Microbiol. 1975;21:1940-1946.

108. Brault SA, Blanchard MT, Gardner IA, et al. The immune response of foals to natural infection with equid herpesvirus-2 and its association with febrile illness. Vet Immunol Immunopathol. 2010;137:136-141.

109. Mumford JA, Rossdale PD. Virus and its relationship to the "poor performance" syndrome. Equine Vet J. 1980;12:3-9.

110. Fortier G, van Erck E, Fortier C, et al. Herpesviruses in respiratory liquids of horses: putative implication in airway inflammation and association with cytological features. Vet Microbiol. 2009;139: 34-41.
111. Ebert MG. Equine herpes virus type 2 (EHV-2): studies on the prevalence in eye swabs and the tissue- and cells tropism, particularly in cases of equine keratoconjunctivitis. Das Equine Herpesvirus Typ. 2006;2 http://www.diss.fu-berlin.de/diss/receive/ FUDISS_thesis_000000002711?lang=en. Accessed February 23, 2015.

112. Fetsch A, Huebner J, Langbein I, Mueller E, Borchers K. [Evaluation of the immune status of horses with and without equine keratoconjunctivitis in particular consideration of an EHV-2 infection]. Tierärztliche Praxis Großtiere. 2007;35:356-362. German.

113. Richter N, Ebert M, Borchers K. Prevalence of EHV-2 and EHV-5 DNA in ocular and nasal swabs as well as peripheral blood mononuclear cells. Pferdeheilkunde. 2009;25:38-44.

114. Rushton JO, Kolodziejek J, Tichy A, Nell B, Nowotny N. Detection of equid herpesviruses 2 and 5 in a herd of 266 Lipizzaners in association with ocular findings. Vet Microbiol. 2013;164:139-144.

115. Sonderegger F, Pot S, Walser-Reinhardt L, et al. The prevalence of DNA of EHV-2 and EHV-5 in horses with keratoconjunctivitis and clinically normal horses in Switzerland. Pferdeheilkunde. 2013;29: 457-459.

116. Collinson PN, O'Rielly JL, Ficorilli N, Studdert MJ. Isolation of equine herpesvirus type 2 (equine gammaherpesvirus 2) from foals with keratoconjunctivitis. J Am Vet Med Assoc. 1994;205: 329-331.

117. Sugiura T, Fukuzawa Y, Kamada M, Ando Y, Hirasawa K. Isolation of equine herpesvirus type 2 from foals with pneumonitis. Bulletin of the Equine Research Institute. 1983;20:148-153.

118. Dunowska M, Wilks CR, Studdert MJ, Meers J. Viruses associated with outbreaks of equine respiratory disease in New Zealand. NZVet J. 2002;50:132-139.

119. Sledge DG, Miller DL, Styer EL, Hydrick HA, Baldwin CA. Equine herpesvirus 2-associated granulomatous dermatitis in a horse. Vet Pathol. 2006;43:548-552.

120. Vengust M, Baird JD, van Dreumel T, Ackerley C, Bienzle D. Equid herpesvirus 2-associated oral and esophageal ulceration in a foal. J Vet Diagn Invest. 2008;20:811-815.

121. Marenzoni ML, Sforna M, Stefanetti V, et al. Detection of equid herpesvirus type 2 and 5 DNA in uterine flushings of mares with reproductive disorders. Vet Microbiol. 2014;174:570-576.

122. Purewal AS, Smallwood AV, Kaushal A, Adegboye D, Edington N. Identification and control of the cis-acting elements of the immediate early gene of equid herpesvirus type 1. J Gen Virol. 1992;73: 513-519.

123. Purewal AS, Smallwood AV, Allsopp R, Welch HM, Edington N. Cross-hybridization of equid herpesvirus-2 (EHV-2) and herpes simplex virus-1 (HSV-1) genes to equid herpesvirus-1 (EHV-1). Vet Microbiol. 1993;35:1-10.

124. Welch HM, Bridges CG, Lyon AM, Griffiths L, Edington N. Latent equid herpesviruses 1 and 4: detection and distinction using the polymerase chain reaction and co-cultivation from lymphoid tissues. J Gen Virol. 1992;73:261-268.

125. Dutta SK, Myrup AC, Thaker SR. In vitro interference between equine herpesvirus types 1 and 2. Am J Vet Res. 1986;47:747-750.

126. McBrearty KA, Murray A, Dunowska M. A survey of respiratory viruses in New Zealand horses. N Z Vet J. 2013;61:254-261.

127. Banbura MW, Witkowski L, Chmielewska A, Tucholska A, Rzewuska M, Ruszczyk A. [Isolation of equine herpesvirus type 1 and 2 (EHV-1 and EHV-2) from foals infected with Rhodococcus equi]. Med Weter. 2004;60:1333-1336. Polish.

128. Dzieciatkowski T. [Influence of equine herpes virus type 2 (EHV-2) on productive infections of equine herpes virus type 1 (EHV-1) in vitro]. Med Weter. 2005;61:338-340. Polish.

129. Varga J, Fodor L, Rusvai M, Soós I, Makrai L. Prevention of Rhodococcus equi pneumonia of foals using two different inactivated vaccines. Vet Microbiol. 1997;56:205-212.

130. Marenzoni ML, Coppola G, Maranesi M, et al. [Equid herpesvirus 5 (EHV-5) infection in 15 foals]. Ippologia. 2010;21:31-34. Italian. 
131. Dunowska M, Holloway SA, Wilks CR, Meers J. Genomic variability of equine herpesvirus-5. Arch Virol. 2000;145:1359-1371.

132. Holloway SA, Lindquester GJ, Studdert MJ, Drummer HE. Identification, sequence analysis and characterisation of equine herpesvirus 5 glycoprotein B. Arch Virol. 1999; 144:287-307.

133. Ruszczyk A, Chmielewska A, Tucholska A, et al. [Occurrence of equine herpesvirus type 5 in Poland - a case study]. Med Weter. 2003;59:236-238. Polish.

134. Diallo IS, Hewitson GR, Jong AD, et al. Equine herpesvirus infections in yearlings in South-East Queensland. Arch Virol. 2008;153: 1643-1649.

135. Herder V, Barsnick R, Walliser U, et al. Equid herpesvirus 5-associated dermatitis in a horse - resembling herpes-associated erythema multiforme. Vet Microbiol. 2012;155:420-424.

136. Kutasi O, Moravszki L, Sardi S, et al. Systemic granulomatous disease in a Hungarian warmblood gelding. J Equine Vet Sci. 2014;34: 810-815.

137. Hart KA, Barton MH, Williams KJ, et al. Multinodular pulmonary fibrosis, pancytopenia and equine herpesvirus- 5 infection in a thoroughbred gelding. Equine Vet Educ. 2008;20:470-476.

138. Sato S, Kawashima $\mathrm{H}$, Oshiro $\mathrm{H}$, et al. Virological and immunological characteristics of a 19-year-old Japanese female with fatal outcome with Epstein-Barr virus-associated hemophagocytic syndrome. J Clin Virol. 2004;31:235-238.

139. Cesarman E. Gammaherpesvirus and lymphoproliferative disorders in immunocompromised patients. Cancer Lett. 2011;305:163-174.

140. Kubiski SV, Rech RR, Camus MS, Pellegrini-Masini A, Elfenbein JR, Howerth EW. Pathology in practice. Interstitial pneumonia with fibrosis and intranuclear inclusion bodies. $\mathrm{J} \mathrm{Am} \mathrm{Vet} \mathrm{Med} \mathrm{Assoc.}$ 2009;235:381-383.

141. Poth T, Niedermaier G, Hermanns W. [Equine multinodular pulmonary fibrosis in association with an EHV-5 infection in 5 horses]. Wien Tierarztl Monatsschr. 2009;96:203-208. German.

142. Niedermaier G, Poth T, Gehlen H. Clinical aspects of multinodular pulmonary fibrosis in two warmblood horses. Vet Rec. 2010;166: 426-430.

143. Verryken K, Saey V, Maes S, et al. [First report of multinodular pulmonary fibrosis associated with equine herpesvirus 5 in Belgium]. Vlaams Diergen Tijds. 2010;79:297-301. Dutch.

144. Lehmbecker A, Biesenbach W, König P, Schneider-Bühl L, Wohlsein P. [Multinodular pulmonary fibrosis in a horse from Schleswig-Holstein]. Tierarztl Prax Ausg G Grosstiere Nutztiere. 2011;39:237-240. German.

145. Marenzoni ML, Passamonti F, Lepri E, et al. Quantification of equid herpesvirus 5 DNA in clinical and necropsy specimens collected from a horse with equine multinodular pulmonary fibrosis. J Vet Diagn Invest. 2011;23:802-806.

146. Tomlinson JE, Divers TJ, McDonough SP, Thompson MS. Hypertrophic osteopathy secondary to nodular pulmonary fibrosis in a horse. J Vet Intern Med. 2011;25:153-157.

147. Back H, Kendall A, Grandon R, et al. Equine multinodular pulmonary fibrosis in association with asinine herpesvirus type 5 and equine herpesvirus type 5: a case report. Acta Vet Scand. 2012;54:57.
148. Schwarz B, Klang A, Bezdekova B, Sárdi S, Kutasi O, Hoven R. Equine multinodular pulmonary fibrosis (EMPF): five case reports. Acta Vet Hung. 2013;61:319-332.

149. Schwarz B, Schwendenwein I, Van Den Hoven R. Successful outcome in a case of equine multinodular pulmonary fibrosis (EMPF) treated with valacyclovir. Equine Vet Educ. 2013;25:389-392.

150. Soare T, Leeming G, Morgan R, et al. Equine multinodular pulmonary fibrosis in horses in the UK. Vet Rec. 2011;169:313.

151. Spelta CW, Axon JE, Begg A, et al. Equine multinodular pulmonary fibrosis in three horses in Australia. Aust Vet J. 2013;91:274-280.

152. Scharner D, Böttcher D, Köhler C, Müller K. [Equine multinodular pulmonary fibrosis in a Shire horse mare]. Prakt Tierarzt. 2012;93: 420-426. German.

153. Kutasi O, Balogh N, Lajos Z, Nagy K, Szenci O. Diagnostic approaches for the assessment of equine chronic pulmonary disorders. $J$ Equine Vet Sci. 2011;31:400-410.

154. Dunowska M, Hardcastle MR, Tonkin FB. Identification of the first New Zealand case of equine multinodular pulmonary fibrosis. NZVet $J$. 2014;62:226-231.

155. Panziera W, Giaretta PR, Galiza GJN, et al. Equine multinodular pulmonary fibrosis associated with equine herpesvirus 5 in a horse in Brazil. Braz J Vet Pathol. 2014;7:17-20.

156. Wong DM, Belgrave RL, Williams KJ, et al. Multinodular pulmonary fibrosis in five horses. J Am Vet Med Assoc. 2008;232:898-905.

157. Wilkins PA. Equine multinodular pulmonary fibrosis: new, emerging or simply recently described? Equine Vet Educ. 2008;20:477-479.

158. Wilkins PA. Equine multinodular pulmonary fibrosis: diagnosis and treatment. Equine Vet Educ. 2013;25:393-397.

159. Dunkel B. Pulmonary fibrosis and gammaherpesvirus infection in horses. Equine Vet Educ. 2012;24:200-205.

160. Naik PN, Horowitz JC, Moore TA, Wilke CA, Toews GB, Moore BB. Pulmonary fibrosis induced by gamma-herpesvirus in aged mice is associated with increased fibroblast responsiveness to transforming growth factor-beta. J Gerontol A Biol Sci Med Sci. 2012;67: 714-725.

161. Kessell AE, Wilkes E, Raidal S, Browne EA, Hughes K. Diagnostic challenge: mare with clinical history of chronic respiratory disease. Severe interstitial pneumonia. Aust Vet J. 2014;92:46-48.

162. Ko S, Kang J-G, Yeh J-Y, et al. First report on molecular detection of equine upper respiratory infectious viruses in Republic of Korea. J Equine Vet Sci. 2013;33:628-636.

163. Bell SA, Pusterla N, Balasuriya UB, Mapes SM, Nyberg NL, MacLachlan NJ. Isolation of a gammaherpesvirus similar to asinine herpesvirus-2 (AHV-2) from a mule and a survey of mules and donkeys for AHV-2 infection by real-time PCR. Vet Microbiol. 2008;130: 176-183.

164. Vengust M, Wen X, Bienzle D. Herpesvirus-associated neurological disease in a donkey. J Vet Diagn Invest. 2008;20:820-823.

165. De Witte FG, Frank N, Wilkes RP, Novak JM. Association of asinine herpesvirus-5 with pyogranulomatous pneumonia in a mare. $J$ Vet Intern Med. 2012;26:1064-1068.
Veterinary Medicine: Research and Reports

\section{Publish your work in this journal}

Veterinary Medicine: Research and Reports is an international, peer-reviewed, open access journal publishing original research, case reports, editorials, reviews and commentaries on all areas of veterinary medicine. The manuscript management system is completely online and includes a very quick and fair peer-review system.

\section{Dovepress}

Visit http://www.dovepress.com/testimonials.php to read real quotes from published authors. 